\title{
Intrastriatal Implantation of Fibroblasts Genetically Engineered to Produce Brain-Derived Neurotrophic Factor Prevents Degeneration of Dopaminergic Neurons in a Rat Model of Parkinson's Disease
}

\author{
Marc Levivier, ${ }^{1,2}$ Serge Przedborski, ${ }^{1}$ Craig Bencsics, ${ }^{3}$ and Un Jung Kang ${ }^{3}$ \\ ${ }^{\prime}$ Neuroscience Research, Movement Disorders Division, Department of Neurology, Columbia University, New York, \\ New York 10032, 'Department of Neurosurgery, Université Libre de Bruxelles, Hôpital Erasme, B-1070 Brussels, \\ Belgium, and, ${ }^{3}$ Departments of Neurology and Pharmacological \& Physiological Sciences, Committee on \\ Neurobiology, The University of Chicago, Chicago, Illinois 60637
}

Parkinson's disease (PD) is a neurodegenerative disorder characterized by a progressive loss of the dopaminergic neurons of the substantia nigra pars compacta (SNpc). Although various treatments are successfully used to alleviate the symptoms of PD, none of them prevents or halts the neurodegenerative process of the disease. Brain-derived neurotrophic factor (BDNF), a member of the neurotrophin family of proteins, supports the survival and the differentiation of dopaminergic neurons. BDNF also prevents the death of dopaminergic neurons in vitro, which suggests that it may be of possible use in the development of neuroprotective therapies for PD. To determine whether BDNF is neuroprotective for SNpc dopaminergic neurons in the adult brain, we used a rat model of PD in which degeneration of $60-70 \%$ of these neurons was induced by an intrastriatal injection of 6-hydroxydopamine (6-OHDA). We report here that intrastriatal grafts of fibroblasts genetically engineered to produce BDNF partially prevent the loss of nerve terminals and completely prevent the loss of cell bodies of the nigrostriatal dopaminergic pathway that is induced by the intrastriatal injection of 6-OHDA. In contrast, the implantation of control fibroblasts that did not produce BDNF failed to protect nerve terminals and cell bodies against 6-OHDA-induced damage. Our observation that grafts of BDNF-producing fibroblasts protect against 6-OHDA-induced degeneration of SNpc dopaminergic neurons in the adult rat brain opens new perspectives for treatments aimed at the prevention of neurodegeneration in PD, using gene therapy and neurotrophic factors such as BDNF.

[Key words: brain-derived neurotrophic factor, neuropro-

Received May 18, 1995; revised Aug. 22, 1995; accepted Ang. 24, 1995.

We are grateful to Prof. Jacques Brotchi (Université Libre de Bruxelles) and Prof. Stanley Fahn (Columbia University) for their support of this project. We thank Dr. Ahmed Maqbool for help with the cell cultures, as well as Danny Young, Hai Ying Fan, and Nathan Goldman for excellent technical assistance. This work is supported by the Parkinson's Disease Foundation (M.L., S.P., U J.K.) the United Parkinson Foundation (U.J.K.), the National Institute of Neurological Disorders and Stroke Grants 1-K08-NS01724-01 (S.P.), R29NS32080 (U.J.K.), the Lowenstein Fundation (S.P.), and the Fonds National de la Recherche Scientifique of Belgium (M.L., S.P.). M.L. is supported by NIH, Fogarty, Fulbright, and NATO fellowships; S.P. is a recipient of the Colonel Berger Junior Investigator Award and the Irving A. Hansen Memorial Foundation Award.

Correspondence should be addressed to Dr. Serge Przedborski, BB-307, 650 West 168th Street, Columbia University, New York, NY 10032.

Copyright (C) 1995 Society for Neuroscience $0270-6474 / 95 / 157810-11 \$ 05.00 / 0$ tection, nigrostriatal lesion, 6-hydroxydopamine, Parkinson's disease, genetically modified cell, transplantation, fibroblast, gene therapy, retroviral vector, quantitative autoradiography, $\left.{ }^{3} \mathrm{H}-\mathrm{mazindol}\right]$

Degeneration of the dopaminergic neurons of the substantia nigra pars compacta $(\mathrm{SNpc})$ and the resulting loss of their nerve terminals in the striatum are responsible for most of the motor disturbances observed in Parkinson's disease (PD), a common ncurodegencrative disorder (Fahn, 1988) of unknown cause (Jenner et al., 1992). The clinical features of PD usually appear when approximately $50 \%$ of the SNpc neurons have degenerated and when $80 \%$ of the striatal dopamine content is depleted (Agid et al., 1987). In most patients, these disabling symptoms can, at least initially, be alleviated by pharmacological dopamine replacement therapies using drugs such as levodopa. Nevertheless, none of these treatments can halt or even slow down the progression of the underlying neurodegenerative process and, in advanced PD, they frequently induce major side-effects (Fahn, 1989).

Neurotrophic factors are endogenous soluble proteins that regulate the survival, growth, and morphological plasticity of neurons, as well as protect neurons against various insults (Lindsay et al., 1994). Thus, neurotrophic factors that specifically prevent degeneration and increase the functional activity of dopaminergic neurons are of substantial interest for the development of new therapeutic strategies for PD (Lindsay et al., 1994). Brain-derived neurotrophic factor (BDNF) is a member of a family of neurotrophic factors called neurotrophins (Glass and Yancopoulos, 1993). In vitro, BDNF promotes the survival and differentiation of fetal mesencephalic dopaminergic neurons, and protects them against 1-methyl-4-phenylpyridinium ion (MPP+)and 6-hydroxydopaminc (6-OHDA)-induced dopaminergic neurotoxicity (Hyman et al., 1991; Knüsel et al., 1991). Although BDNF prevents in vivo the axotomy-induced loss of septo-hippocampal cholinergic neurons (Knüsel et al., 1992; Morse et al., 1993) and of spinal motor neurons (Sendtner et al., 1992; Yan et al., 1992), its neuroprotective effect on dopaminergic neurons in living animals remains, thus far, poorly defined. In vivo delivery of BDNF by parenchyma infusion of the recombinant proteins failed to protect dopaminergic neurons from axotomyinduced degeneration (Kniisel et al., 1992; Lapchak et al., 1993), but increased dopaminergic functional activity and turnover in normal animals (Altar et al., 1992). We have shown that genet- 
ically modified primary fibroblast cells that express BDNF are effective delivery vehicles for the neurotrophic factor and promotc sprouting of tyrosine hydroxylase $(\mathrm{TH})$-immunoreactive fibers from the dopaminergic neurons in vivo (Lucidi-Phillipi et al., 1995). However, these BDNF-expressing cells were unable to protect dopaminergic neurons from the toxicity of 6-OHDA infused into medial forebrain bundle which leads to nearly complete lesion of dopaminergic neurons. On the other hand, genetically modified immortalized fibroblast cell lines were used to demonstrate that BDNF protects dopaminergic neurons from MPP+ toxicity in vivo (Frim et al., 1994) and intrastriatal infusion of BDNF attenuated the toxicity of intrastriatal 6-OHDA (Shults et al., 1995). Some of the observed discrepancies could be due to (1) the differences in the mechanism of cell death from different insults such as MPP+, 6-OHDA, and axotomy; (2) the severity of the lesion; or (3) the characteristics of delivery systems.

The goal of the present study was to further define the effect of these genetically modified primary cells expressing BDNF on SNpc dopaminergic neurons in the adult brain, a question we thought of importance as ultimately this approach is more applicable to the clinical situations than immortalized cell lines or chronic infusion by implantation of cannula. Neurotrophic factors are most helpful in the early stage of the disorder, when there are remaining cells to be saved. Therefore, we employed a rat model of PD which reflects the early stagcs of PD (Przedborski et al., 1995) which is generated by intrastriatal injection of 6-OHDA to create partial lesion of the dopaminergic system. The neuroprotective effect of BDNF on 6-OHDA-induced dopaminergic degeneration of the nigrostriatal pathway was assessed by utilizing binding autoradiography to quantify the density of dopamine uptake sites in both the striatum and the SNpc, and Nissl staining to determine the total number of SNpc neurons.

\section{Materials and Methods}

Chemicals. All tritiated compounds were purchased from Ncw England Nuclear (Boston, MA). Nomifensine maleate was generously provided by Hoechst-Roussel (Somerville, NJ) and ketanserin tartrate by Janssen Pharmaceutical (Beerse, Belgium). 6-OHDA hydrobromide was purchased from Regis (Morton Grove, IL). Cis-( $\mathrm{Z}$ )-flupentixol-2HCl was purchased from Research Biochemical International (Natick, MA). All other chemicals were purchased from standard commercial sources and were cell culture or molecular biological grade.

Animals. Adult male Fischer 344 rats (Harlan Sprague-Dawley) weighing $220-225 \mathrm{gm}$ at the beginning of the experiment were used. They were housed four per cage in a temperature-controlled room with a $12 \mathrm{hr}$ light-dark cycle, and had free access to food and water. This experimental protocol was approved by the Animal Care and Use Committee of Columbia University and is in agreement with the guidelines from the National Institutes of Hcalth for the use of live animals.

Genetic modification of fibroblasts to produce BDNF. Primary cultures of rat dermal fibroblasts were prepared from skin biopsies obtained from inbred Fischer 344 rats, as described (Kawaja and Gage, 1992) They were grown in Dulbecco's minimal essential medium (DMEM) supplemented with $10 \%$ fetal bovine serum, $0.3 \mathrm{mg} / \mathrm{ml}(2 \mathrm{~mm})$ glutamate, $2.5 \mu \mathrm{g} / \mathrm{ml}$ amphotericin, and $40 \mathrm{mg} / \mathrm{ml}$ gentamycin (supplemented DMEM) in an incubator $\left(10 \% \mathrm{CO}_{2}\right)$ at $37^{\circ} \mathrm{C}$. Primary fibroblasts were infected with the recombinant retrovirus containing the entire coding region of the human BDNF gene (LBdnfRNL; Fig. $1 A$ ), as previously described (Lucidi-Phillipi et al., 1995). Briefly, the plasmid LBdnfRNL was lipofected into the $\psi-2$ ecotropic packaging cell line by I ipofectin (BRL/GIBCO Laboratories), and conditioned medium from the cells was then used to infect the amphotropic cell line, PA-317. Clones of PA-317 cells were selected in the presence of $400 \mu \mathrm{g} / \mathrm{ml}$ of Geneticin (G-418 Sulfate; BRL/GIBCO Laboratories), and the conditioned medium was used to infect Rat 1 cell lines to assay for virus titer; PA-317

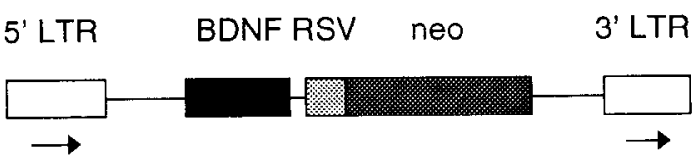

$1 \mathrm{~kb}$
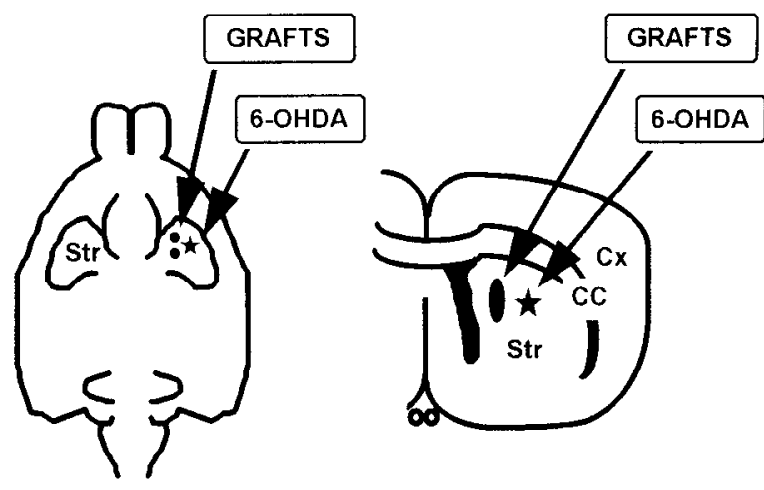

Figure 1. A, Schematic map of the retroviral plasmid used to transfect the -2 packaging cells. The $830 \mathrm{bp}$ EcoRI-BamHI fragment containing the entire coding region of human BDNF (Jones and Reichardt, 1990) was ligated into the vector LRNL downstream from the viral $5^{\prime}$ long terminal repeat ( $L T R)$ (LBdnfRNL). The selection marker aminoglycoside phosphotransferase (neo) is controlled by an internal Rous sarcoma virus (RSV) promoter. $B$, Schematic representation of transversal (left) and coronal (right) sections of a rat brain at the level of the striatum (Str), illustrating the sites of implantation of fibroblasts (GRAFTS) and the site of injection of 6-OHDA injection (6-OHDA) into the striatum. Fibroblasts are implanted in two sites into the right striatum; 2 weeks later, 6-OHDA is injected into the ipsilateral striatum, in a site midway and lateral to the two grafts. $C C$, Corpus callosum; $C x$, cortex.

subclones showing the highest titer were selected. The primary rat fibroblasts were infected by incubation in conditioned medium from the selected packaging cell lines in $4 \mu \mathrm{g} / \mathrm{ml}$ polybrene. After $24 \mathrm{hr}$, successfully transfected fibroblasts (BDNF $[+]$ fibroblasts) were selected in the presence of $400 \mu \mathrm{g} / \mathrm{ml}$ G-418 and grown to confluence. Nontransduced fibroblasts (BDNF[-] fibroblasts) from identical biopsies served as control. The selected BDNF[+] fibroblasts were screened for their level of BDNF mRN $\Lambda$ production by Northern blot analysis, as previously (Lucidi-Phillipi et al., 1995).

Effect of BDNF produced by the genetically modified fibroblasts on fetal mesencephalic cultures. To confirm the production of biologically active human BDNF by the BDNF[+] fibroblasts, we used cultures of rat fetal ventral mesencephalon. Ventral mesencephalic neurons from the mesencephalic flexure of E15 rat fetuses were dissected out, dissociated in $0.1 \%$ trypsin solution, and plated at a concentration of 50,000 cells $/ \mathrm{cm}^{2}$ on poly-D-lysine-coated plates in $\mathrm{N} 2.1$ medium after a $24 \mathrm{hr}$ incubation in DMEM supplemented with $10 \%$ fetal calf serum. Cultures were then incubated in media conditioned by either BDNF[+] fibroblasts or BDNF[-] fibroblasts. After $5 \mathrm{~d}$, cultures were fixed in 4\% paraformaldehyde in phosphate-buffered saline $(\mathrm{pH} 7.4)$ and immunostained for tyrosine hydroxylase (TH; PelFreeze, 1:750). TH-immunoreactive neurons were counted manually under light microscopy $(200 \times)$ along the entire length of 6-well plates at regular intervals.

Preparation and intrastriatal implantation of fibroblasts. The day of 
the transplantation experiment, fibroblasts in culture were washed, trypsinized and suspended in Dulbecco's phosphate-buffered saline at the final concentration of 105 cells $/ \mu \mathrm{l}$. Viability was assessed by trypan blue dye exclusion before implantation of the cells into the host brain. Adult male Fischer 344 rats (220-250 gm, Harlan Sprague-Dawley) were anesthetized with pentobarbital $(50 \mathrm{mg} / \mathrm{kg}$, i.p.), had their heads shaved, and were placed in a Kopf stereotaxic apparatus (incisor bar: $-3.3 \mathrm{~mm}$ ). The scalp was cleaned with an iodine solution, incised on the midline, and a burr hole was drilled through the skull at the appropriate location. For each rat, a total of $2 \mu \mathrm{l}$ of a cell suspension containing either $\mathrm{BDNF}[+]$ or $\mathrm{BDNF}[-]$ fibroblasts was delivered in two sites $(1 \mu \mathrm{l} / \mathrm{site})$ into the right intact striatum, at a rate of $0.5 \mu \mathrm{l} / \mathrm{min}$ using a $10 \mu \mathrm{l}$ Hamilton syringe. Coordinates for the implantation of fibroblasts were: $\mathrm{A} / \mathrm{P}=10.6$ (anterior graft) and $9.0 \mathrm{~mm}$ (posterior graft), LAT $=-2.0 \mathrm{~mm}$, from interaural; $\mathrm{V}=-5.5 \mathrm{~mm}$ from dura, according to Paxinos and Watson (Paxinos and Watson, 1986). At the end of the implantation procedure, the needle was left in place for 2 min before being slowly withdrawn. The wound was closed with stainless steel clips, and the rats were allowed to recover before being returned to their cages.

Induction of a partial lesion of the nigrostriatal dopaminergic pathway. Two weeks after implantation of fibroblasts, rats received an intrastriatal injection of 6-OHDA, as previously described (Przedborski et al., 1995). Using a stereotactic procedure similar to that described above for transplantation, $3.5 \mu \mathrm{l}$ of a 6-OHDA solution $(2.5 \mu \mathrm{g} / \mu \mathrm{l}$ freebase, dissolved in $0.9 \% \mathrm{NaCl}$ containing $0.02 \%$ ascorbic acid, and maintained on ice and protected from light until injection) was injected into the striatum ipsilateral to transplantation, in a site equidistant from and lateral to the two grafts $(\mathrm{A} / \mathrm{P}=9.8 \mathrm{~mm}$, LAT $=-2.5 \mathrm{~mm}$, from Interaural; $\mathrm{V}=-5.5 \mathrm{~mm}$ from dura) (Paxinos and Watson, 1986).

Experimental groups assignment. In order to test the neuroprotective effect of BDNF on 6-OHDA-induced toxicity, rats received grafts of $\mathrm{BDNF}[+]$ fibroblasts prior to the injection of 6-OHDA (BDNF[-]/6OHDA group; $n=7$ ), using the techniques described above. Control groups consisted of (1) animals which received no grafts prior to the injection of 6-OHDA (6-OHDA only group; $n=8$ ), (2) animals which received grafts of BDNF $[+]$ fibroblasts but no subsequent injection of $6-$ OHDA (BDNF[+] only group; $n=4$ ), and (3) animals which received grafts of BDNF[-] fibroblasts prior to the injection of 6-OHDA (BDNF[-]/6-OHDA group; $n=8$ ).

Tissue preparation. Three weeks after lesioning (5 weeks after the grafting procedure), all rats were sacrificed by decapitation. The brains were rapidly removed, rinsed in ice-cold saline, frozen in isopentane cooled on dry ice, and stored at $-80^{\circ} \mathrm{C}$ until sectioning. Coronal sections $(20 \mu \mathrm{m})$ were cut in a cryostat at $-20^{\circ} \mathrm{C}$, thaw-mounted onto gelatin-coated glass slides (two sections per slide), dried at $4 \Psi$ under negative pressure for $2 \mathrm{hr}$ and then kept in a sealed slide box at $-80^{\circ} \mathrm{C}$ until use (at least $72 \mathrm{hr}$ ). To assess the regional distribution of BDNFmediated neuroprotective effect, sections were taken at five different rostrocaudal planes at the level of the striatum $(10.7,10.2,9.7,9.2$, and $8.7 \mathrm{~mm}$ from interaural line) and of three planes at the level of SNpc $(4.2,3.7$, and $3.2 \mathrm{~mm}$ from interaural line) of each brain (Paxinos and Watson, 1986). Radioligand binding assays were performed on adjacent sections from the same brain region and each radioligand binding was performed in each of the animals.

Autoradiographic binding assays. Dopamine uptake sites were labeled with ${ }^{3} \mathrm{H}$-mazindol $(15.0 \mathrm{Ci} / \mathrm{mmol})$ according to our previously described method (Przedborski et al., 1991). Sections were preincubated at $4^{\circ} \mathrm{C}$ for $15 \mathrm{~min}$ in $50 \mathrm{~mm}$ Tris- $\mathrm{IICl}$ (pI 7.9) containing $120 \mathrm{mM} \mathrm{NaCl}$ and $5 \mathrm{mM} \mathrm{KCl}$. They were then incubated at $4^{\circ} \mathrm{C}$ for $60 \mathrm{~min}$ in $50 \mathrm{~mm}$ Tris- $\mathrm{HCl}$ (pH 7.9) containing $300 \mathrm{~mm} \mathrm{NaCl}, 5 \mathrm{~mm} \mathrm{KCl}, 300 \mathrm{nM}$ desmethylimipramine (to block binding to norepinephrine uptake sites), and $4 \mathrm{~nm}{ }^{3} \mathrm{H}$-mazindol. The sections were then washed twice ( $3 \mathrm{~min}$ each) in ice-cold buffer, dipped in ice-cold distilled water, and rapidly dried under a stream of cold air. Nonspecific binding was defined as that occurring in the presence of $100 \mu \mathrm{M}$ nomifensine $(<20 \%$ of total binding).

Dopamine D1 receptors were labeled with ${ }^{3} \mathrm{H}-\mathrm{SCH} 23390(72.8 \mathrm{Ci} /$ $\mathrm{mmol}$ ) according to our previously described method (Przedborski et al., 1991). The sections were preincubated at $25^{\circ} \mathrm{C}$ for $10 \mathrm{~min}$ in 50 $\mathrm{mM}$ Tris- $\mathrm{HCl}(\mathrm{pH} \mathrm{7.4)}$ containing $120 \mathrm{~mm} \mathrm{NaCl}, 5 \mathrm{mM} \mathrm{KCl}, 2 \mathrm{~mm}$ $\mathrm{CaCl}_{2}, 1 \mathrm{mM} \mathrm{MgCl}$. They were then incubated at $25^{\circ} \mathrm{C}$ for $60 \mathrm{~min}$ in the same buffer containing $50 \mathrm{~nm}$ of ketanserin (to block binding to serotonin-2 receptors) and $1.25 \mathrm{~nm}{ }^{3} \mathrm{H}-\mathrm{SCH} 23390$. The sections were then washed twice ( $5 \mathrm{~min}$ each) in ice-cold buffer, dipped in ice-cold distilled water, and rapidly dried under a stream of cold air. Nonspecitic binding was defined as that occurring in the presence of $1 \mu \mathrm{M} \operatorname{cis}(Z)$ flupentixol ( $<5 \%$ of total binding).

Autoradiography and image analysis. After labeling, the dried sections were apposed to tritium-sensitive film (Hyperfilm, Amersham) in light-proof $\mathrm{x}$-ray cassettes, along with tritium plastic standards $\left({ }^{3} \mathrm{H}-\mathrm{Mi}\right.$ cro-scales, Amersham). After $12 \mathrm{~d}$ to 6 weeks at $25^{\circ} \mathrm{C}$, the films were developed with Kodak D-19 developer and fixed with Kodak Rapid Fix. Five different coronal planes in the forebrain and three in the mesencephalon were examined for each rat. Within each section, brain regions were defined according to a standard rat brain atlas: striatum, nucleus accumbens, olfactory tubercle, substantia nigra, and ventral tegmental area. The mid-striatum was subdivided along its longest dorsoventral and mediolateral axes into dorsolateral, dorsomedial, ventrolateral, and ventromedial quadrants (Przedborski et al., 1991). Each region was outlined with a screen cursor driven by a hand-held mouse, as previously described (Przedborski et al., 1991). Optical densities were quantified using a computerized image analysis system (Inquiry image analyzer, Loats Associates, Westminster, MD), and were converted to femtomoles of radioligand bound per milligram of tissue equivalent using a standard curve ( ${ }^{3} \mathrm{H}$-Micro-scales). For each rat, each coronal plane, and each radioligand, readings from four separate sections were obtained and averaged for total and nonspecific binding. For each rat and each coronal plane, striatal and graft area $\left(\mathrm{mm}^{2}\right)$ was determined from the digitized images and from the Nissl-counterstained section.

After autoradiographic studies, representative sections used for the receptor binding assays were stained with thionin for Nissl substance and used for anatomic reference.

Quantitative morphology. For each animal, mesencephalic sections adjacent to those used for the ${ }^{3} \mathrm{H}$-mazindol binding were stained with thionin for Nissl substance. SNpc cells were counted as previously described (Przedborski et al., 1995). For each rat and each representative mesencephalic plane, Nissl-stained neurons were manually counted in the SNpc on at least four different sections (light microscopy; 400X) by scanning the full extent of the SNpc for both the experimental and nonexperimental sides using a superimposed grid to facilitate the procedure. These counts were then averaged to give the mean number of SNpc neurons per representative plane and per rat. For each rat, the mean number of neurons per representative planes were then summed to give an index of the total number of $\mathrm{SNpc}$ neurons per rat. Because the SNpc merges with the ventral tegmental area (VTA) at its medial border in planes 4.2 and 3.2 (Przedborski et al., 1995), we defined the boundary between the two nuclei in these planes as a line extending dorsally from the most medial boundary of the cerebral peduncle. In plane 3.7 (Przedborski et al., 1995), the SNpc and the VTA are separated by white matter bundles, the medial lemniscus and the tractus opticus basalis. Neurons were only counted if they stained above background and if they contained a nucleus surrounded by cytoplasm. Counting was done blind to the surgical procedures received.

The area of neurons in the SNpc was determined as described previously (Przedborski et al., 1995). For each animal, the area of 15-40 representative SNpc neurons was assessed on both the experimental and the nonexperimental sides using a Nikon Microphot microscope at a magnification of $600 \times$ coupled to the Inquiry image analyzer. Only neurons with a complete nucleus in the plane of the section were assessed, to avoid neurons not fully profiled in the section plane. Each neuron was outlined with a screen cursor driven by a hand-held mouse (Przedborski et al., 1995); proximal dendrites were included in the measurements up to a point where the dendrite width tapered to less than one micrometer. Values of neuronal areas were used to determined whether an $\Lambda$ bercrombie correction (Abercrombie, 1946) would be required to compare neuron counts between the experimental and the control sides.

Statistical analyses. All values are expressed as the mean \pm SEM. For in vitro experiments, statistical differences between means of the two conditions of culture were tested using a two-tailed Student's $t$ test, to confirm the bioactivity of the secreted BDNF. For each group (in vivo experiments), the values for experiemental and intact contralateral sides were compared using a two-tailed Student's $t$ test for paired samples. Differences among means were analyzed using one-way ANOVA with the different treatments as the independent factor. When ANOVA showed significant differences, pair-wisc comparisons between means were tested by Newman-Keuls post-hoc testing. In all analyses the null hypothesis was rejected at the 0.05 level. All statistical analyses were 

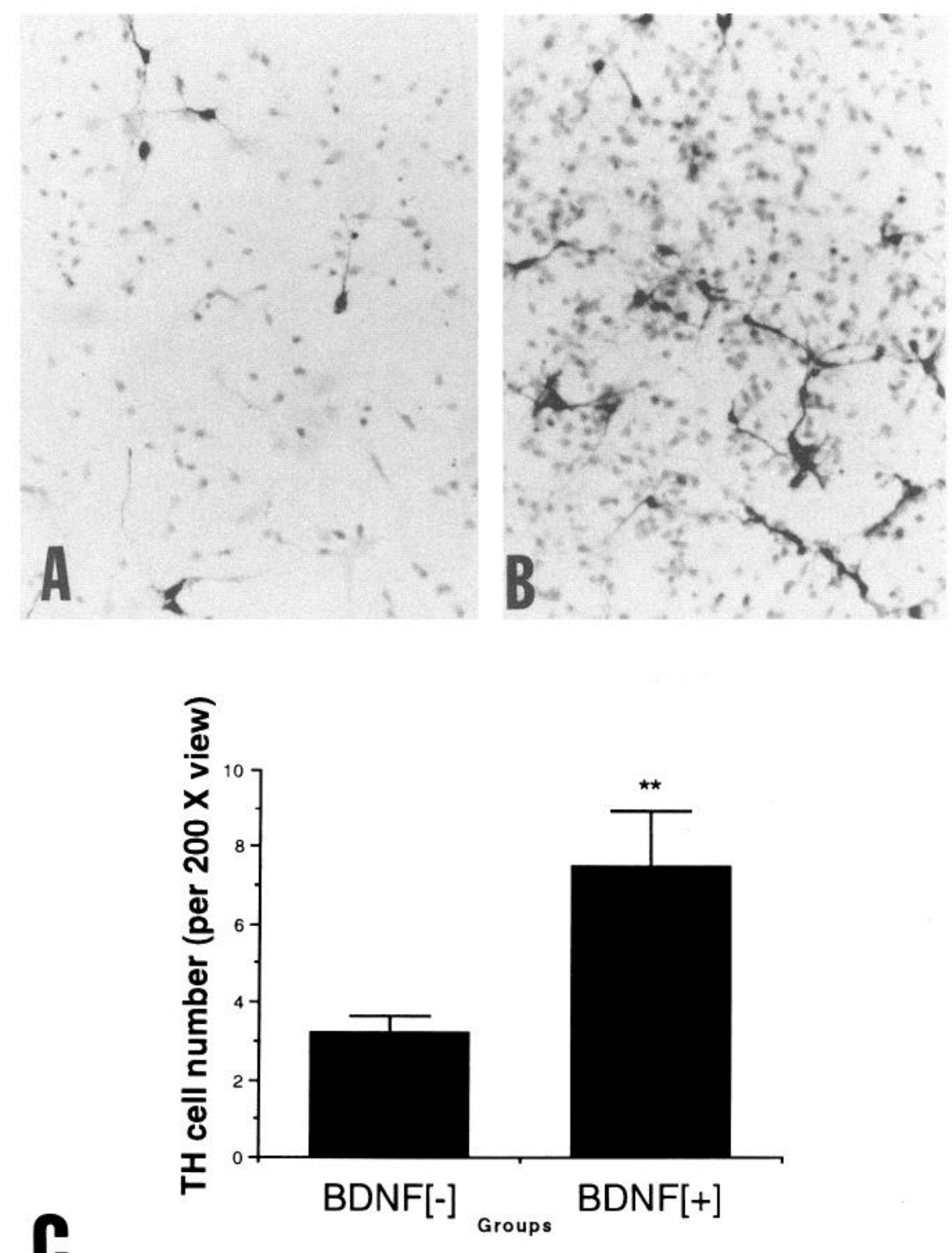

Figure 2. Microphotographs of cocultures of rat fetal ventral mesencephalic neurons with control (BD$\mathrm{NF}[-])$ fibroblasts $(A)$ and BDNF-producing (BDNF[+]) fibroblasts $(B)$, and immunostained for tyrosine hydroxylase $(T H)$, illustrating the biological neurotrophic effect of BDNF produced by the transduced fibroblasts. $C$, Bar graph of the quantification of the effect of BDNF produced by the transduced fibroblasts on fetal mesencephalic neurons in culture. The number (mean \pm SEM) of TH-immunoreactive cells is significantly higher in mesencephalic cultures incubated in media conditioned by $\mathrm{BDNF}[+]$ fibroblasts than in cultures incubated in media conditioned by $\mathrm{BDNF}[-]$ fibroblasts. ${ }^{* *}, p$ $<0.01$.

performed using SIGMASTAT FOR WINDOWs (version 1.0, Jandel Corporation, San Rafael, CA).

\section{Results}

Production of biologically active human BDNF by the $\mathrm{BDNF}[+]$ fibroblasts has been well established in our previous publications and reconfirmed here by the Northern blot analysis (data not shown) and by its neurotrophic effect on fetal rat dopaminergic mesencephalic neurons in culture (Fig. 2A,B). The number of tyrosine-hydroxylase-immunoreactive cells was significantly higher in mesencephalic cultures incubated in media conditioned by $\mathrm{BDNF}[+]$ fibroblasts than in cultures incubated in media conditioned by BDNF[-] fibroblasts (Fig. 2C).

In all groups, examination of coronal sections showed normal and symmetrical macroscopic morphology of the forebrain (Fig. $3)$. Neither at the level of the graft nor at the level of the injection of 6-OHDA (Fig. 3), did the experimental side show any significant reduction in cross-sectional area compared to the controlateral intact side (less than $10 \% ; p>0.05$ ). In all transplanted rats, grafts were easily identified in Nissl-stained sections
(Fig. $3 B$ ), traversing the overlying cerebral cortex and the corpus callosum, and reproducibly reaching the striatum at the target coordinates. At the level of the transplantation coordinates, the size of the each of the two grafts constituted less than $12 \%$ of the ipsilateral striatal cross-sectional area. In rats transplanted with $\mathrm{BDNF}[+]$ or $\mathrm{BDNF}[-]$ fibroblasts, the grafts appeared composed of numerous spindle-shaped, heavily Nissl-stained cells (Fig. $3 C$ ), consistent with their being healthy fibroblasts. These fibroblasts appeared intermingled with few glial cells, but no neurons were seen (Fig. $3 C$ ). The grafts corresponded to areas devoid of ${ }^{3} \mathrm{H}-\mathrm{SCH} 23390$ binding on the autoradigrams (Fig. 3A) and were excluded from all binding quantification. Except for a fine and discrete network of glial cells surrounding the grafts, the rest of the experimental striatum showed a normal organization, a normal density of neurons (Fig. 3C), and a concentration of ${ }^{3} \mathrm{H}-\mathrm{SCH} 23390$ binding similar to that of the control side (Fig. 3A).

In all injected rats, needle tracks were also easily identified in Nissl-stained sections (Fig. $3 E$ ) and reproducibly reached the 

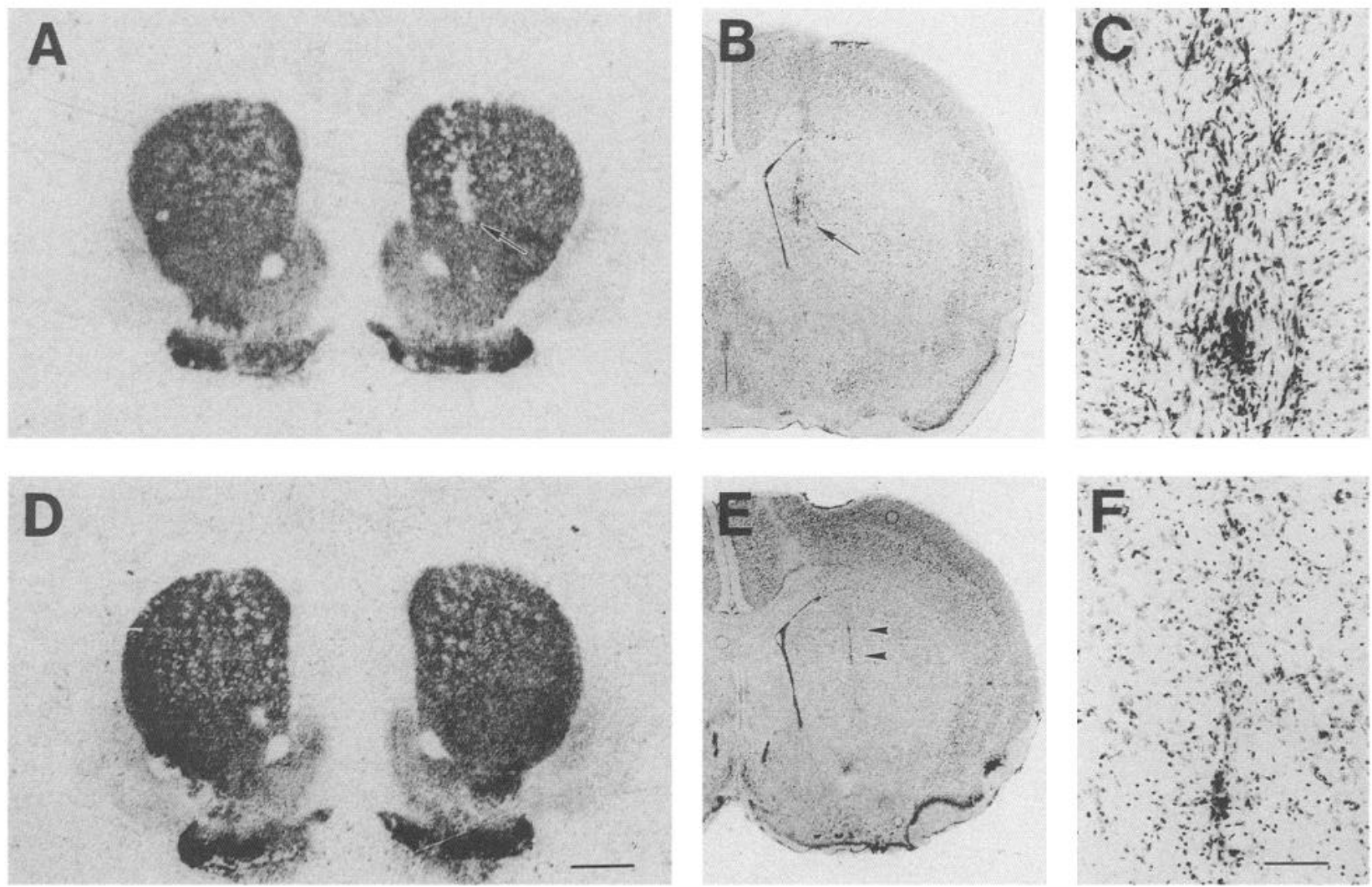

Figure 3. A-C, Representative ${ }^{3} \mathrm{H}-\mathrm{SCH} 23390$-generated autoradiogram and Nissl-stained section at the level of a graft of BDNF[+]-producing fibroblasts. A, ${ }^{3} \mathrm{H}-\mathrm{SCH} 23390$ binding appears unaffected in the experimental striatum compare to the contralateral control side, except at the level of the graft where no binding is seen (arrow). B. In Nissl-stained section, the graft appears as a small hypechromatic area (arrow). $C$, At higher magnification, the graft appears healthy and the surrounding host striatum not markedly altered. $D-F$, Representative ${ }^{3} \mathrm{H}-\mathrm{SCH} 23390$-generated autoradiogram and Nissl-stained section at the level of the injection of 6-OHDA, illustrating that the local injection did not affect the binding of ${ }^{3} \mathrm{H}-\mathrm{SCH} 23390(D)$ and correspond to a thin hyperchromatic area (arrowheads, E), or gliosis with a complete loss of intrinsic neurons $(F)$. The rest of the striatum appears normal $(F)$. Scale bars: $A, B, D$, and $E, 1.5 \mathrm{~mm} ; C$ and $F, 100 \mu \mathrm{m}$.

striatum at the target coordinates. The needle tracks were surrounded by an oval, heavily Nissl-stained area (Fig. 3E,F), which constituted less than $3 \%$ of the ipsilateral striatal crosssectional area. This area is composed of numerous cells with small, hyperchromatic nuclei, consistent with their being glial cells, and did not contain neurons (Fig. $3 F$ ). This area did not contain foci of necrosis (Fig. $3 F$ ). In almost all of the rats, the heavily Nissl-stained area was not visible on ${ }^{3} \mathrm{H}-\mathrm{SCH} 23390$ binding-generated autoradiograms (Fig. 3D). Consistent with our previous study (Przedborski et al., 1995), the rest of the experimental striatum was unremarkable (Fig. $3 D-F$ ). Although in this study it was not possible to obtain all serial sections, the relative distances between the two grafts and the site of injection of 6-OHDA were quite consistent among rats and, as mentioned above, agreed well with the targeted coordinates.

Injection of 6-OHDA into the striatum of rats (6-OHDA only group) induced significant reductions of ${ }^{3} \mathrm{H}$-mazindol binding concentrations on the ipsilateral striatum (Fig. 4A). As previously observed (Przedborski et al., 1991), intrastriatal injection of 6-OHDA causes reduction of ${ }^{3} \mathrm{H}$-mazindol binding concentrations which is maximal at the site of injection and which lessens progressively with distance from that site (Fig. 5). In these animals, marked reductions of ${ }^{3} \mathrm{H}$-mazindol binding concentrations and Nissl-stained neuronal count (Fig. 6A, Table 1) in the ipsilateral SNpc were also observed. These changes were slightly more pronounced in the rostral end as compared to the caudal end of the SNpc (Table 1).

In BDNF[+]/6-OHDA animals, the loss of striatal dopaminergic nerve terminals was markedly, but not completely, prevented (Fig. $4 C$ ) compared to 6-OHDA only animals (Fig. 4A). Analysis of the anteroposterior distribution of ${ }^{3} \mathrm{H}$-mazindol binding concentrations in the striatum (Fig. 5) showed that BDNF[+] fibroblasts provided greater protection at increasing distances from the 6-OHDA injection site; maximal protection was observed at $1 \mathrm{~mm}$ from the 6-OHDA injection site (BDNF[+]/6OHDA animals: $96 \pm 5 \%$, vs 6 -OHDA only animals: $54 \pm 4 \%$ ), while minimum protection was observed in the coronal planes immediately adjacent to the site of injection (BDNF[+]/6OHDA animals: $37 \pm 3 \%$ vs 6-OHDA only animals: $24 \pm 2 \%$ ). Although injection of 6-OHDA and transplantation of BDNF[+] fibroblasts were both performed in the striatum, the most dramatic protective effect of BDNF on 6-OHDA-mediated dopaminergic neurotoxicity was observed at the level of the SNpc (Fig. 6, Table 1). At the level of the most caudal plane of the SNpc (i.e., interaural 3.2), ${ }^{3} \mathrm{H}$-mazindol binding concentrations and Nissl-stained neuronal counts on the experimental side were almost identical to those of nonlesioned animals (BDNF only group), and at the level of the most rostral plane of the SNpc (i.e., interaural 4.2), both markers were preserved by more than $50 \%$. 

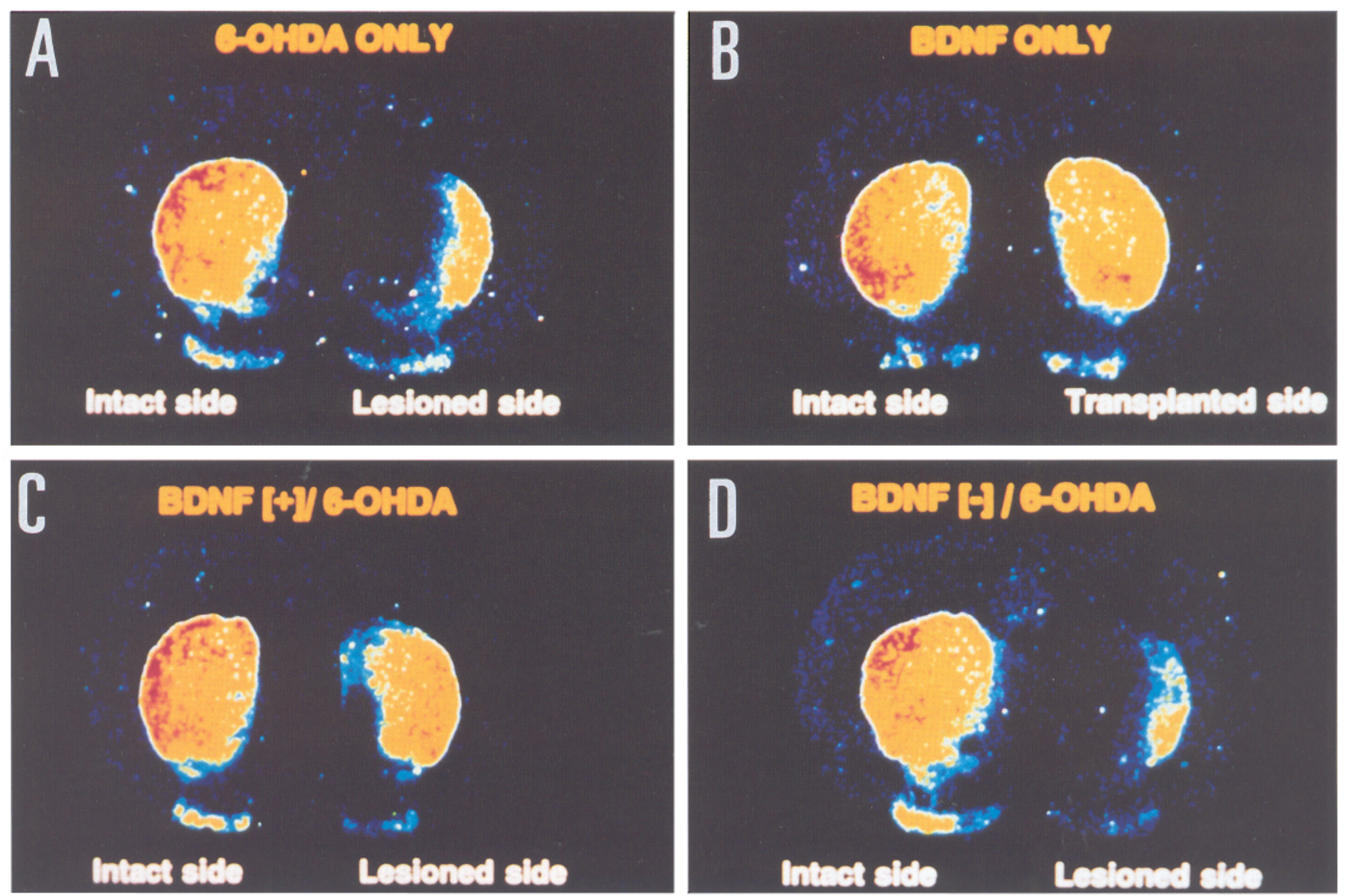

Figure 4. $A-D$, Representative color-coded transformed autoradiograms illustrating the effect of a unilateral injection of 6-OHDA into the striatum on ${ }^{3} \mathrm{H}$-mazindol-labeled dopamine uptake sites binding at the level of the mid striatum. $A$, In nongrafted animals (6-OHDA only), there is a marked reduction in binding concentrations on the 6-OHDA injected side compared to the contralateral control (intact) side. $C$, In contrast, in animals which received grafts of $\mathrm{BDNF}[+]$ fibroblasts two weeks before the injection of 6-OHDA (BDNF[+]/6-OHDA), binding concentrations are minimally affected as they are almost identical to those of the contralateral intact side. $B$, In control animals which received grafts of BDNF[ +$]$ fibroblasts but no injection of 6-OHDA (BDNF[+] only), binding concentrations on the transplanted side do not differ from those of the contralateral intact side. $D$, Moreover, in animals which received grafts of BDNF[-] fibroblasts prior to the injection of 6-OHDA (BDNF[-]/6-OHDA), binding concentrations on the 6-OHDA-injected side were as reduced as in 6-OHDA only animals.

In contrast to the protection provided by grafts of $\mathrm{BDNF}[+]$ fibroblasts, grafts of $\mathrm{BDNF}[-]$ fibroblasts failed to protect against 6-OHDA-induced dopaminergic neurotoxicity. In the BDNF[-]/6-OHDA animals, the experimental side showed reductions in striatal ${ }^{3} \mathrm{H}$-mazindol binding concentrations (Figs. $4 D, 5$ ), and in nigral ${ }^{3} \mathrm{H}$-mazindol binding concentrations and Nissl-stained neuronal counts comparable to that seen in 6-OHDA only animals (Fig. 6D, Table 1).

In $\mathrm{BDNF}[+]$ only animals, the experimental side showed striatal ${ }^{3} \mathrm{H}$-mazindol binding concentrations (Figs. $4 B, 5$ ), and nigral ${ }^{3} \mathrm{H}$-mazindol binding and Nissl-stained neuronal counts not different from those of the contralateral nongrafted side (Fig. $6 B$, Table 1).

\section{Discussion}

In the present study, we have constructed and used primary rat fibroblasts that produce human BDNF in sufficient amounts to exert neurotrophic action on dopaminergic neurons in culture (Fig. 2). Implantation of these fibroblasts into the striatum of rats was then used as a cellular vector for intrastriatal delivery of BDNF (Fig. 1). Nissl-stained sections showed that these grafts remained healthy and integrated well within the host brain 5 weeks following implantation (Fig. 3), in agreement with our previous observation (Lucidi-Phillipi et al., 1995). Using this technique, we demonstrate that BDNF-producing grafts implanted 2 weeks prior to an intrastriatal injection of 6-OHDA protect against the degeneration of the nigrostriatal dopaminergic pathway.

Previously, we have found that a surgical grafting procedure, when performed 1 week prior to the intrastriatal injection of 6-OHDA, attenuates 6-OHDA-induced dopaminergic neurotoxicity (Przedborski et al., 1991). Trauma-induced neuroprotection decreases rapidly over time (Levivier et al., 1995) and seems to be related to the extent of the surgical trauma (unpublished observation). Here, in an attempt to avoid this effect, animals were injected with 6-OHDA 2 weeks after the implantation procedure, and the latter was performed with a thinner needle. On the other hand, the expression of transgene from viral promoters in grafted fibroblasts is limited in time. We have previously demonstrated good expression up to 2 weeks in vivo by in situ hybridization (Lucidi-Phillipi et al., 1995). Therefore, a 2 week time point was the most optimal one in that the toxin was injected after 2 weeks of BDNF exposure, after the nonspecific effect had subsided, and before the suppression of the transgene expression was sig- 


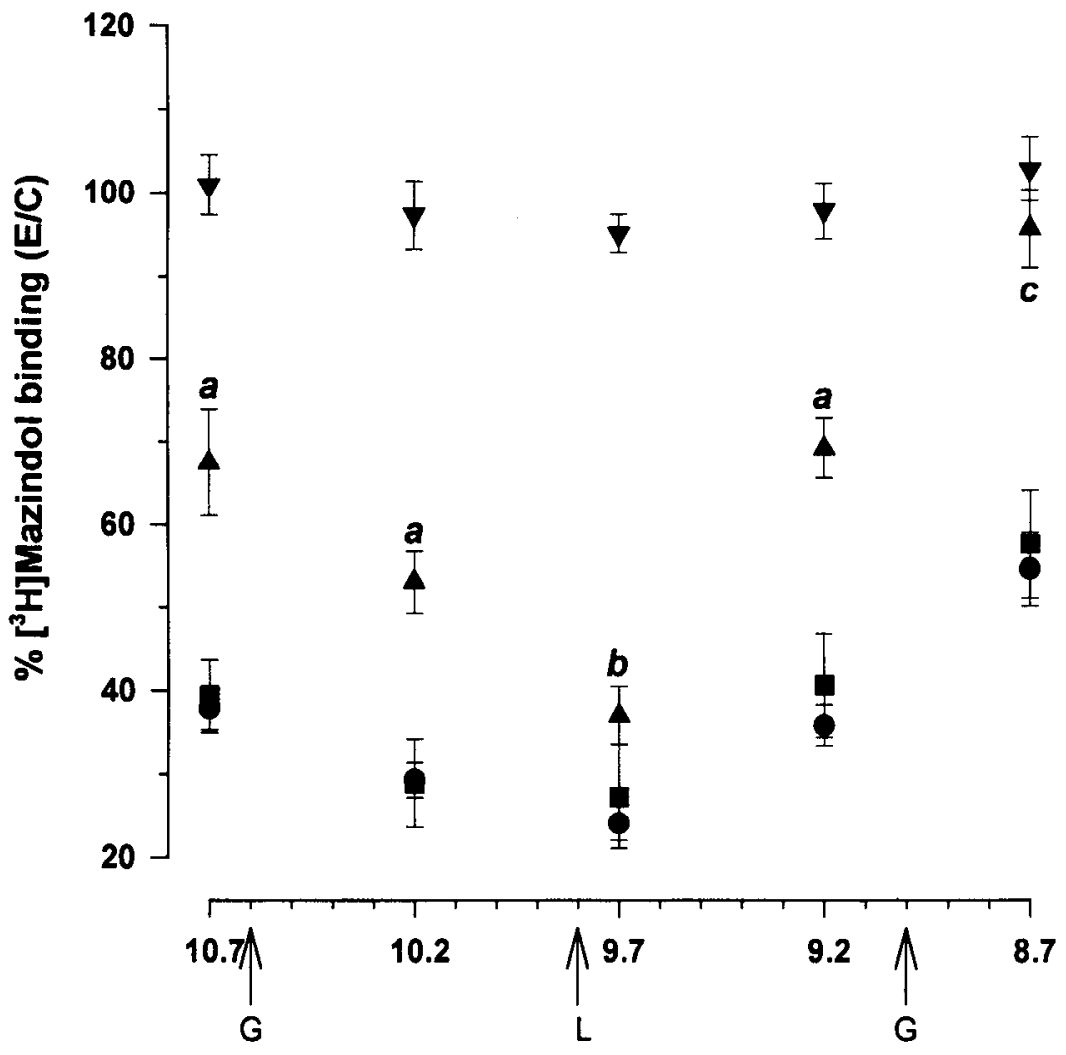

Striatal coronal plane (Interaural, $\mathrm{mm}$ )

Figure 5. Etfect of the unilateral injection of 6-OHDA on ${ }^{3} \mathrm{H}$ ]mazindol-labeled dopamine uptake sites binding at the different anteroposterior level of the striatum. In non-grafted animals (6-OHDA only; ), there is a marked reduction in ${ }^{3} \mathrm{H}$-mazindol binding concentrations at the level of striatum in all coronal planes. In contrast, in animals which received grafts of BDNF[+] fibroblasts 2 weeks before the injection of 6-OHDA (BDNF[+]/6-OHDA; $\boldsymbol{\Delta}),{ }^{3} \mathrm{H}$-mazindol binding concentrations were significantly higher with maximal protection seen at distance from the site of 6-OHDA injection. Except for the most posterior coronal plane, striatal ${ }^{3} \mathrm{H}$-mazindol binding concentrations, did not reach the values observed in nonlesioned animals (BDNF[+] only; $\boldsymbol{\nabla}$ ). In those control animals which received grafts of BDNF[ + ] fibroblasts but no injection of 6-OHDA (BDNF $[+]$ only), ${ }^{3} \mathrm{H}$-mazindol binding concentrations on the transplanted side did not differ from the contralateral intact side. In animals which received grafts of BDNF[- ] fibroblasts and an injection of 6-OHDA (BDNF[-]/6-OHDA; $\boldsymbol{\square}$ ), ${ }^{3} \mathrm{H}$-mazindol binding concentrations were as reduced as in 6 OHDA only animals in all coronal planes. Values represent means \pm SEM and are expressed as percentage of controlaletral control side. $G$, Graft; $L$, injection of 6-OHDA. Signficantly different $(p<0.05$; Newman-Keuls post-hoc test) from: $a$, BDNF only, 6-OHDA only, and BDNF[-]/6-ONHDA groups; $b$, BDNF only group; $c, 6-\mathrm{OHDA}$ only and BDNF[-]/6-ONHDA groups.

\begin{tabular}{|c|c|c|c|c|c|c|c|c|c|}
\hline \multirow{2}{*}{$\begin{array}{l}\text { Experimental } \\
\text { group }\end{array}$} & \multicolumn{3}{|c|}{ Plane $4.2 \mathrm{~mm}$} & \multicolumn{3}{|c|}{ Plane $3.7 \mathrm{~mm}$} & \multicolumn{3}{|c|}{ Plane $3.2 \mathrm{~mm}$} \\
\hline & $\mathrm{C}$ & $\mathrm{E}$ & $\mathrm{E} \% \mathrm{C}$ & $\mathrm{C}$ & $\mathrm{E}$ & $\mathrm{E} \% \mathrm{C}$ & $\mathrm{C}$ & $\mathrm{E}$ & $\mathrm{E} \% \mathrm{C}$ \\
\hline \multicolumn{10}{|c|}{ 6-OHDA only $(n=8)$} \\
\hline${ }^{3} \mathrm{H}$-Mazindol & $318 \pm 18$ & $73 \pm 16^{a}$ & $23 \pm 6$ & $324 \pm 22$ & $97 \pm 18^{a}$ & $30 \pm 5^{a}$ & $303 \pm 22$ & $104 \pm 14^{a}$ & $34 \pm 5$ \\
\hline Nissl & $99 \pm 11$ & $32 \pm 8^{a}$ & $32 \pm 3^{e}$ & $148 \pm 9$ & $53 \pm 10^{a}$ & $36 \pm 2^{e}$ & $113 \pm 7$ & $54 \pm 7^{a}$ & $48 \pm 5^{e}$ \\
\hline \multicolumn{10}{|c|}{ BDNF only $(n=4)$} \\
\hline${ }^{3} \mathrm{H}-\mathrm{Mazindol}$ & $299 \pm 14$ & $306 \pm 16^{b}$ & $102 \pm 3$ & $319 \pm 19$ & $322 \pm 21^{b}$ & $100 \pm 7$ & $281 \pm 16$ & $279 \pm 17^{c}$ & $99 \pm 7$ \\
\hline Nissl & $106 \pm 8$ & $104 \pm 7^{c}$ & $98 \pm 4$ & $136 \pm 5$ & $128 \pm 6^{c}$ & $94 \pm 6$ & $107 \pm 7$ & $103 \pm 6$ & $96 \pm 2$ \\
\hline \multicolumn{10}{|c|}{$\mathrm{BDNF}[+] / 6-\mathrm{OHDA}(n=7)$} \\
\hline${ }^{3} \mathrm{H}$-Mazindol & $303 \pm 21$ & $158 \pm 16^{r}$ & $52 \pm 3^{f}$ & $324 \pm 17$ & $214 \pm 18^{c}$ & $66 \pm 4^{c}$ & $293 \div 20$ & $240 \pm 14^{c}$ & $82 \pm 7$ \\
\hline Nissl & $94 \pm 9$ & $62 \pm 8^{c}$ & $66 \pm 4^{d}$ & $141 \pm 8$ & $103 \pm 7^{c}$ & $73 \pm 6$ & $112 \pm 6$ & $99 \pm 9$ & $88 \pm 8$ \\
\hline \multicolumn{10}{|c|}{ BDNF[-]/6-OHDA $(n=8)$} \\
\hline${ }^{3} \mathrm{H}-\mathrm{Mazindol}$ & $312 \pm 8$ & $94 \pm 6^{a}$ & $30 \pm 3 f$ & $336 \pm 22$ & $87 \pm 18^{a}$ & $26 \pm 8$ & $313 \pm 25$ & $110 \pm 20^{a}$ & $35 \pm 6 r$ \\
\hline Nissl & $100 \pm 7$ & $34 \pm 6^{a}$ & $34 \pm 7^{e}$ & $144 \pm 9$ & $56 \pm 5^{a}$ & $39 \pm 2 e$ & $102 \pm 7$ & $48 \pm 7^{a}$ & $47 \pm 4$ \\
\hline
\end{tabular}

Values represent $\mathrm{fmol} / \mathrm{mg}$ tissue equivalent for ${ }^{3} \mathrm{H}$-mazindol binding and number of Nissl-stained neurons in the SNpc and are expressed as means \pm SEM for $4-$ 8 rats per group. Planes correspond to coordinate from interaural line according to Paxinos and Watson (1982). C, control intact side; E, experimental side; E\%C, experimental value divided by control value multiplied by 100 . Significantly different $\left(p<0.05\right.$; Newman-Keuls post-hoc test) from: ${ }^{2}$ BDN ${ }^{\circ}$ only and BDNF[ 1$] /$ 6-OHDA groups; ${ }^{b}$ all other groups; ${ }^{6} 6$-OHDA only and BDNF[-]/6-OHDA groups. Significantly different (paired Student's $t$ test) from the control intact side at

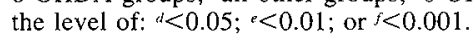


nificant. These factors are clearly limitations of current approach for ultimate application to clinical situations since the window of opportunity is very narrow. However, the focus of these experiments was to demonstrate that BDNF can be delivered intraparenchymally by genetically modified cells and BDNF can protect dopaminergic neurons in partial lesion models which mirrors the early stage of Parkinson's disease. Such cellular vector system for BDNF is particularly critical since BDNF is rapidly taken up by truncated trkB receptors and limits its diffusion in the parenchyrira.

To support the interpretation that the observed protection is indeed mediated by BDNF produced by the grafted fibroblasts rather than by the grafting procedure itself, a group of animals received grafts of $\mathrm{BDNF}[-]$ fibroblasts prior to the injection of 6-OHDA. These BDNF[-]/6-OHDA animals were not protected against the neurotoxic effect of 6-OHDA, as they exhibited a degree of dopaminergic damage to both nerve terminals and cell bodies similar to that observed in 6-OHDA only animals. Since in vivo delivery of BDNF near or into the SNpc increases dopamine turnover and tyrosine hydroxylase-positive fiber density (Altar et al., 1992; Lucidi-Phillipi et al., 1995), it was also important to examine whether intrastriatal delivery BDNF in our experimental paradigm had altered the dopamine uptake site density, as measured using quantitative autoradiography for ${ }^{3} \mathrm{H}$ mazindol, or the number of SNpc neurons, which would be a confounding factor in interpreting our results. In BDNF only animals, we did not find any significant difference between the data in the grafted and non-grafted sides, suggesting that BDNF itself did not alter the parameters measured in this study.

A major afferent system to SNpc neurons is the striatonigral pathway (Graybiel, 1990). This pathway not only provides chemical input to neurons in the $\mathrm{SNpc}$, but possibly also neurotrophic support. Since intrastriatal injection of 6-OHDA can cause damage to neurons of the striatonigral pathway (Przedborski et al., 1995) and since striatal dopamine D1 receptors are expressed predominantly by these neurons (Gerfen et al., 1990), we assessed the status of this pathway using quantitative autoradiography for ${ }^{3} \mathrm{H}-\mathrm{SCH} 23390$. We did not find any significant change in ${ }^{3} \mathrm{H}-\mathrm{SCH} 23390$ binding"concentrations among groups. Moreover, analysis of Nissl-stained sections showed minimal morphological abnormalities, such as intrastriatal neuronal loss, diffuse gliosis, or foci of necrosis, except for a small area of gliosis along the needle tract. Altogether, this suggests that the striatonigral pathway remained essentially intact after intrastriatal injection of $3.5 \mu \mathrm{l}$ of $2.5 \mu \mathrm{g} / \mu \mathrm{l}$ 6-OHDA. This view is consistent with our previous work (Przedborski et al., 1995), showing excellent preservation of the striatum following intrastriatal injection of this dose.

There is increasing evidence suggesting that BDNF and other neurotrophins have neuroprotective effects against a large variety of brain insult and that there is an endogenous increase of neurotrophins in response to brain insults intended to protect against cell death (Lindvall et al., 1994). However, the actual molecular mechanisms that underlie neurotrophin-mediated neuroprotection remain thus far speculative. Enhanced BDNF signaling, via the high-affinity tyrosine kinase receptors TrkB, may trigger cellular protective responses, such as preservation of calcium homeostasis, prevention of energetic metabolism failure, and others (Lindvall et al., 1994). The neurotoxic effect 6-OHDA is mediated by the production of free radicals (Cohen et al., 1974). Thus, it is possible that BDNF renders dopaminergic neurons more resistant to 6-OHDA by increasing the cel- lular protective mechanisms implicating free radical scavenging systems (Spina et al., 1992). This hypothesis is consistent with the recent demonstration that BDNF also protects SNpc dopaminergic neurons in vivo against MPP+ (Frim et al., 1994), a neurotoxin suggested to produce free radicals (Hasegawa et al., 1990; Przedborski et al., 1992). Also, the observation that in the BDNF only group, the concentrations in ${ }^{3} \mathrm{H}$-mazindol-labeled dopamine uptake sites remained unchanged, suggests that BDNF did not interfere with the uptake of 6-OHDA by the dopaminergic terminals.

Our ability to introduce BDNF locally by genetically modified cells represents a significant advance in terms of improving the diffusion and creating a minimally disruptive delivery system. Although diffusion of BDNF in brain tissue is limited (Morse et al., 1993), our study shows that relatively widespread dopaminergic protection can be mediated by two circumscribed intrastriatal BDNF-producing grafts (each of which constitutes less than $12 \%$ of the ipsilateral striatal cross-sectional area) transplanted $0.8 \mathrm{~mm}$ away from the sitc of 6-OHDA injection. The profile of protection was bell-shaped in the striatum; less protection near the site of 6-OHDA injection, away from the graft site and more protection at the most anterior and posterior planes near the grafts, away from the 6-OHDA injection site (Fig. 5). Such regional differences in the preservation of the dopaminergic nerve markers are most likely to be a balance between the amount of BDNF and the amount of 6-OHDA available in a specific volume, with the highest neurotoxicity near the site of 6-OHDA injection and highest neuroprotection near the site of BDNF production. In the SNpc (Table 1), a gradient was noted in anteroposterior directions with more pronouced protection in the most posterior plane than in the most anterior plane. Projections from the anterior SNpc tend to lie dorsolaterally and projections from the posterior SNpc tend to lie dorsomedially in the anterior striatum (Gerfen et al., 1987). Since the grafts were more medial and 6-OHD $\Lambda$ more lateral, the greater protection observed in the medial striatum and therefore in the posterior SNpc could be envisioned. However, the exact topography of the nigrostriatal projections to the striatum is complex and multidimensional in that anteroposterior axis and mediolateral axis are intertwined and it is difficult to carry the interpretation of the gradient in the SNpc beyond this simple explanation.

In addition, the protective effect of BDNF against 6-OHDAinduced toxicity was more pronounced on the nigral dopaminergic cell bodies than on the striatal dopaminergic nerve terminals. The reason for the discrepancy between the striatal and nigral neuroprotective effect of BDNF could be severalfold. As we discussed previously (Jackson-Lewis et al., 1995), cells may lose the expression of dopaminergic phenotype, as noted by $\mathrm{TH}$ immunohistochemistry or ${ }^{3} \mathbf{H}$-mazindol binding, but survive as evidenced by other morphological criteria such as Nissl staining. We have used the autoradiographic labeling of the dopamine uptake sites as a quantitative marker of the dopaminergic system. The modulation of expression of the dopaminergic uptake sites, such as their downregulation after injection of 6-OHDA or their upregulation induced by BDNF, may hinder the evaluation of the loss of nigrostriatal neurons, as discussed previously (Przedborski et al., 1995). At the level of the SNpc, we found parallel changes between ${ }^{3} \mathrm{H}$-mazindol binding concentrations and Nisslstained neuronal counts in all experimental groups, confirming that the observed BDNF-induced neuroprotection reflects neuronal preservation rather than increased dopaminergic marker expression. At the level of the striatum, however, the situation 

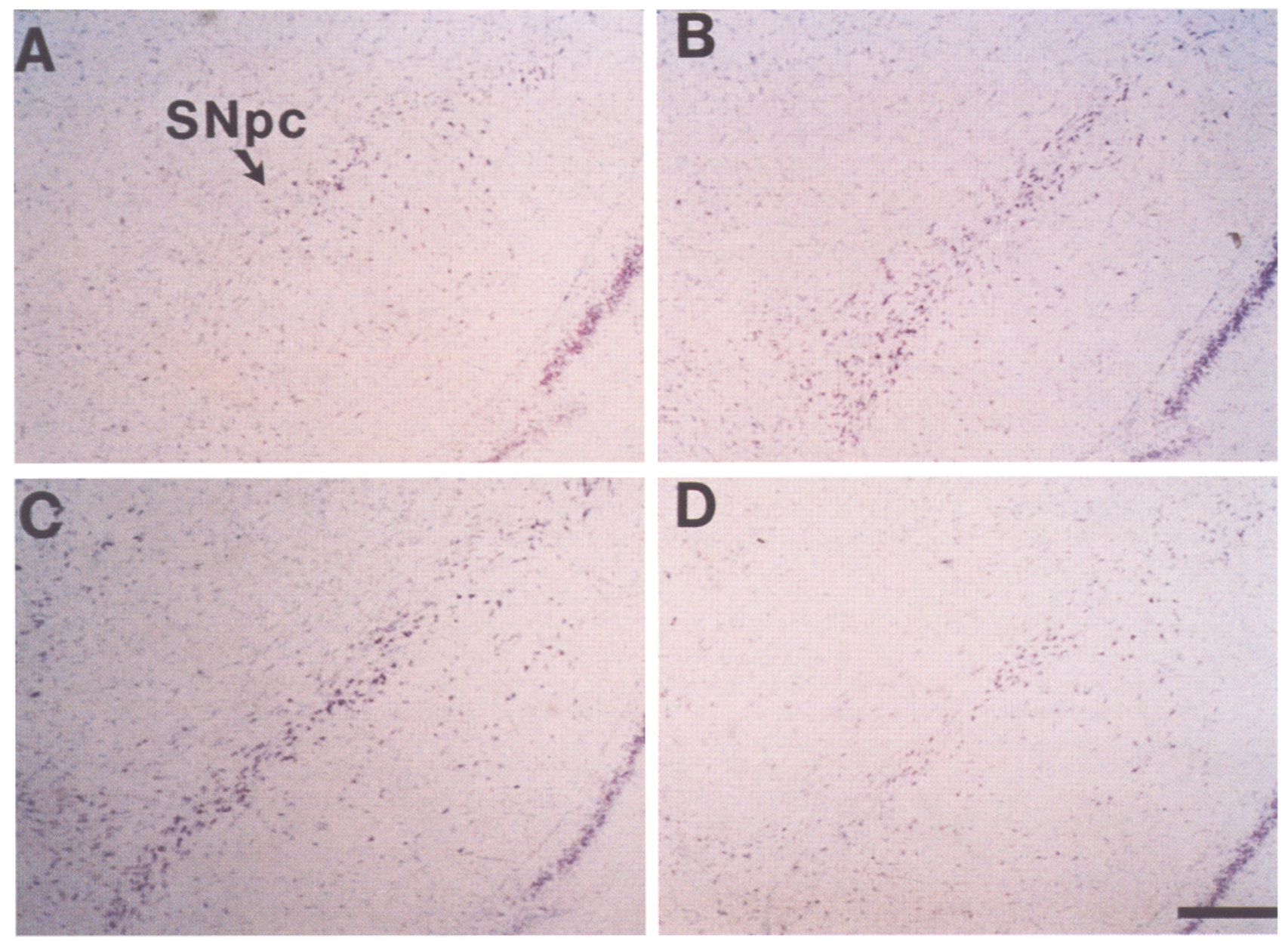

Figure 6. Representative Nissl-stained sections at the level of the SNpc illustrating the effect of a unilateral injection of 6-OHDA into the striatum on the SNpc neuronal population. In nongrafted animals (6-OHDA only), there is a marked reduction in the density of SNpc Nissl-stained neurons (A). In contrast, in animals which received grafts of BDNF[+] fibroblasts 2 weeks before the injection of 6-OHDA (BDNF[+]/6-OHDA), the density of SNpc Nissl-stained neurons is much greater $(C)$ and it is almost identical to that in animals which received grafts of BDNF[+] fibroblasts but no injection of 6-OHDA (BDNF[+] only) $(B)$. Moreover, in animals which received grafts of BDNF[-] fibroblasts prior to the injection of 6-OHDA (BDNF[-]/6-OHDA) $(D)$, the density of SNpc Nissl-stained neurons is as reduced as in 6-OHDA only animals.

is more difficult to interpret because of the lack of an easily identifiable general anatomical marker of nerve terminals. We thus cannot exclude that BDNF may have protected all dopaminergic terminals against 6-OHDA-induced degeneration, but that only some of them expressed a significant number of dopaminc uptake sites at the time of tissue preparation. Further work studying the time-course of the partial protective effect of BDNF on dopaminergic nerve terminals, using ${ }^{3} \mathrm{H}$-mazindol or a morphological dopaminergic marker, such as $\mathrm{TH}$, may help to elucidate this issue. Alternatively, retrograde transport of BDNF and/or 6-OHDA in the nigrostriatal dopaminergic system may yield to different mechanisms of neuroprotection and/or neurotoxicity between the striatal nerve terminals and the SNpc cell bodies.

The relative specificity of the in vitro and in vivo neurotrophic effect of BDNF for dopaminergic neurons is well illustrated. The extent and specificity of the in vivo protective effect of BDNF remains, however, poorly defined. For example, although BDNF prevents neurodegeneration of the septo-hippocampal cholinergic neurons (Knüsel et al., 1992; Morse et al., 1993) and of the spinal motor neurons (Sendtner et al., 1992; Yan et al., 1992), it fails to protect dopaminergic neurons in axotomy models
(Knüsel et al., 1992; Lapchak et al., 1993). Also, previous attempts to show protection of BDNF against near-complete lesions by 6-OHDA have failed (Altar et al., 1994; Lucidi-Phillipi et al., 1995). Recently, Frim et al. (1994) reported that BDNF protects SNpc cell bodies against the neurotoxicity induced MPP+ which was injected into the striatum. This paradigm of lesioning produced, however, large damage to the striatal afferents and efferents which were not affected by BDNF. The lesion model used in the present study resembles early stages of Parkinson's disease (Przedborski et al., 1995), both in the pattern of neuronal loss (Agid et al., 1987) and the proposed mechanism of neurodegeneration, oxidative stress (Fahn and Cohen, 1992). This model may then be adequate to test neuroprotective strategies aimed at slowing down or preventing neurodegeneration early in the course of PD. Using this model, we found that grafts of fibroblasts genetically modified to produce BDNF are able to significantly protect the $\mathrm{SNpc}$ cell bodies and to partially protect the striatal nerve terminals against 6-OHDA-induced dopaminergic neurotoxicity. Since most of the cell bodies were preserved, one can expect reparative mechanisms to take place, allowing a progressive restoration of a normal dopaminergic nerve terminal network. Intrastriatal grafting of various cells in- 
cluding fibroblast cells have been well demonstrated to be without major side effects in animal models and humans. Modified experimental paradigms using delivery of BDNF in greater amounts or for a longer period, or in combination with other dopaminergic neuroprotective factors (Pezzoli et al., 1991; Hagg and Varon, 1993; Beck et al., 1995; Du et al., 1995; Tomac et al., 1995), may enhance its protection on dopaminergic nerve terminals. Thus, our results strongly suggest that BDNF may have an important role in the development of new therapeutic approaches aimed at the prevention of neurodegeneration in early stages of PD.

\section{References}

Abercrombie M (1946) Estimation of nuclear population from microtome sections. Anat Rec 94:239-247.

Agid Y, Javoy-Agid F, Ruberg M (1987) Biochemistry of neurotransmitters in Parkinson's disease. In: Movement disorders 2 (Marsden CD, Fahn S, eds), pp 166-230. London: Butterworths.

Altar CA, Boylan CB, Fritsche M, Jones BE, Jackson C, Wiegand SJ, Lindsay RM, Hyman C (1994) Efficacy of brain-derived neurotrophic factor and neurotrophin-3 on neurochemichal and behavioral deficits associated with partial nigrostriatal dopamine lesions. J Neurochem 63:1021-1032.

Altar CA, Boylan CB, Jackson C, Hershenson S, Miller J, Wiegand SJ, Lindsay RM, Hyman C (1992) Brain-derived neurotrophic factor augments rotational behavior and nigrostriatal dopamine turnover in vivo. Proc Natl Acad Sci USA 89:11347-11351.

Beck KD, Valverde J, Alexi T, Poulsen K, Moffat B, Vandien RA, Rosenthal A, Hefti F (1995) Mesencephalic dopamincrgic neurons protected by GDNF from axotomy-induced degeneration in the adult brain. Nature 373:339-341.

Cohen G, Heikkila RE, Carlstedt T (1974) The generation of hydrogen peroxide, superoxide radical, and hydroxyradical by 6-hydroxydopamine, dialuric acid, and related cytotoxic agents. J Biol Chem 249: $2447-2452$.

Du X, Stull ND, Iacovitti L (1995) Brain-derived neurotrophic factor works coordinately with partner molecules to initiate tyrosine hydroxylase expression in striatal neurons. Brain Res 680:229-233.

Fahn S (1988) The extrapyramidal disorders. In: Cecil textbook of medicine (Wyngaarden JB, Smith LH, eds), pp 2141-2152. Philadelphia: Sauders.

Fahn S (1989) Adverse effects of levodopa in Parkinson's disease. In: Handbook of experimental pharmacology, Vol 8 (Calne DB, ed), pp 386-409. Berlin: Springer.

Fahn S, Cohen G (1992) The oxidant stress hypothesis in Parkinson's disease: evidence supporting it. Ann Neurol 32:804-812.

Frim DM, Uhler TA, Galpern WR, Beal MF, Breakefield XO, Isacson O (1994) Implanted fibroblasts genetically engineered to produce brain-derived neurotrophic factor prevent 1-methyl-4-phenylpyridinium toxicity to dopaminergic neurons in the rat. Proc Natl Acad Sci USA 91:5104-5108.

Gerfen CR, Herkenham M, and Thibault J (1987) The neostriatal mosaic. II. Patch- and matrix-directed mesostriatal dopaminergic and non-dopaminergic systems. I Neurosci 7:3915-3934.

Gerfen CR, Engber TM, Mahan LC, Susel Z, Chase TN, Monsma FJ, Sibley DR (1990) D1 and D2 dopamine receptors-regulated gene expression of striatonigral and striatopallidal neurons. Science 250: 1429-1432.

Glass DJ, Yancopoulos GD (1993) The neurotrophins and their receptors. Trends Cell Biol 3:262-268.

Graybiel AM (1990) Neurotransmitters and neuromodulators in the basal ganglia. Trends Neurosci 13:244-254.

Hagg T, Varon S (1993) Ciliary neurotrophic factor prevents degeneration of adult rat substantia nigra dopaminergic neurons in vivo. Proc Natl Acad Sci USA 90:6315-6319.

Hasegawa E, Takeshige K, Oishi T, Murai Y, Minikami S (1990) 1 Methyl4-phenylpyridium (MPP+) induces NADH dependent superoxide formation and enhances NADH-dependent lipid peroxidation in beef haert submitochondrial particles. Biochem Biophys Res Commun 170:1049-1055.

Hyman C, Hofer M, Barde Y-A, Juhasz M, Yancopoulos GD, Squinto SP, Lindsay RM (1991) BDNF is a neurotrophic factor for dopaminergic neurons of the substantia nigra. Nature 350:230-232.
Jackson-Lewis V, Jakowec M, Burke RE, Przedbroski S (1995) Time course and morphology of dopaminergic neuronal death caused by neurotoxin 1-methyl-4-phenyl-1,2,3,6-tetrahydropyridine. Neurodegeneration, in press.

Jenner P, Schapira AHV, Marsden CD (1992) New insights into the cause of Parkinson's disease. Neurology 42:2241-2250.

Jones KR, Reichardt LF (1990) Molecular cloning of a human gene that is a member of the nerve growth factor family. Proc Natl Acad Sci USA 87:8060-8064.

Kawaja MD, Gage FH (1992) Morphological and neurochemical features of cultured primary skin fibroblasts of Fischer 344 rats following striatal implantation. J Comp Neurol 317:102-116.

Knaasel B, Winslow J, Rosenthal A, Burton L, Seid D, Nikolics K, Hefti F (1991) Promotion of central cholinergic and dopaminergic neuron differentiation by brain-derived neurotrophic factor but not neurotrophin 3. Proc Natl Acad Sci USA 88:961-965.

Knüsel B, Beck KD, Winslow JW, Rosenthal A, Burton LE, Widmer HR, Nikolics K, Hefti F (1992) Brain-derived neurotrophic factor administration protects basal forebrain cholinergic but not nigral dopaminergic neurons from degenerative changes after axotomy in the adult rat brain. J Neurosci 12:4391-4402.

Lapchak PA, Beck KD, Araujo DM, Irwin I, Langston JW, Hefti F (1993) Chronic intranigral administration of brain-derived neurotrophic factor produces striatal dopaminergic hypofunction in unlesioned adult rats and fails to attenuate the decline of striatal dopaminergic function following medial forebrain bundle transection. Neuroscience 53:639-650.

Levivier M. Gash DM, Przedborski S (1995) Time-course of the neuroprotective effect of transplantation on quinolinic acid-induced lesion of the striatum. Neuroscience 69:43-50.

Lindsay RM, Altar CA, Cedarbaum JM, Hyman C, Wiegand SJ (1993) The therapeutic potential of neurotrophic factors in the treatment of Parkinson's disease. Exp Neurol 124:103-118.

Lindsay RM, Wiegand SJ, Altar CA, DiStefano PS (1994) Neurotrophic factors: from molecule to man. Trends Neurosci 17:182-190.

Lindvall O, Kokaia Z, Bengzon J, Elmér E, Kokaia M (1994) Neurotrophins and brain insults. Trends Neurosci 17:490-496.

Lucidi-Phillipi CA, Gage FH, Shults CW, Jones KR, Reichardt LF, Kang UJ (1995) BDNF-transduced fibroblasts: production of BDNF and effects of grafting to the adult rat brain. J Comp Neurol 354:361376.

Morse JK, Wiegand SJ, Anderson K, You Y, Cai N, Carnahan J, Miller J, DiStefano PS, Altar CA, Lindsay RM, Alderson RF (1993) Brainderived neurotrophic factor (BDNF) prevents the degeneration of medial septal cholinergic neurons following fimbria transection. J Neurosci 13:4146-4156.

Paxinos G, Watson C (1986) The rat brain in stereotaxic coordinates. New York: Academic.

Pezzoli G, Zecchinelli A, Ricciardi S, Burke RE, Fahn S, Scarlato G, Carenzi A (1991) Intraventricular infusion of epidermal growth factor restores dopaminergic pathway in hemiparkinsonian rats. Movement Dis 6:281-287.

Przedborski S, Levivier M, Kostic V, Jackson-Lewis V, Dollison A, Gash DM, Fahn S, Cadet JL (1991) Sham transplantation protects against 6-hydroxydopamine-induced dopaminergic toxicity in rats: behavioral and morphological evidence. Brain Res 550:231-238.

Przedborski S, Kostic V, Jackson-Lewis V, Cadet JL, Burke RE (1991) Effect of unilateral perinatal hypoxic-ischemic brain injury in the rat on dopamine D1 and D2 receptors and uptake sites: a quantitative autoradiographic study. J Neurochem 57:1951-1961.

Przedborski S, Kostic V, Jackson-Lewis V, Naini AB, Simonetti S, Fahn S, Carlson E, Epstein CJ, Cadet JL (1992) Transgenic mice with increased $\mathrm{Cu} / \mathrm{Zn}$-superoxide dismutase activity are resistant to $\mathrm{N}$-methyl-4-phenyl-1,2,3,6 tetrahydropyridine induced neurotoxicity. J Neurosci 12:1658-1667.

Przedborski S, Levivier M, Jiang H, Ferreira M, Jackson-Lewis V, Donaldson D, Togasaki DM (1995) Partial lesions of the dopaminergic nigrostriatal pathway induced by intrastriatal injection of 6-hydroxydopamine: rotational behavior, quantitative autoradiography, and histology. Neuroscience 67: 63l-647.

Sendtner M, Holtmann B, Kolbeck R, Thoenen H, Barde Y-A (1992) Brain-derived neurotrophic factor prevents the death of motoneurons in newborn rats after nerve section. Nature 360:757-759.

Shults CW, Kimber T, Altar CA (1995) BDNF attenuates the effects 
of intratsriatal injection of 6-hydroxydopamine. Neuroreport 6:11091112.

Spina MB, Squinto SP, Miller J, Lindsay RM, Hyman C (1992) Brainderived neurotrophic factor protects dopamine neurons against 6-hydroxydopamine and N-methyl-4-phenylpyridinium ion toxicity: involvement of the glutathione system. J Neurochem 59:99-106.
Tomac A, Lindquist E, Lin LH, Ögren S-O, Young D, Hoffer BJ, Olsun $L$ (1995) Protection and repair of the nigrostriatal dopaminergic system by GDNF in vivo. Nature 373:335-339.

Yan Q, Elliott J, Snider WD (1992) Brain-derived neurotrophic factor rescues spinal motor neurons from axotomy-induced cell death. $\mathrm{Na}$ ture 360:753-755. 